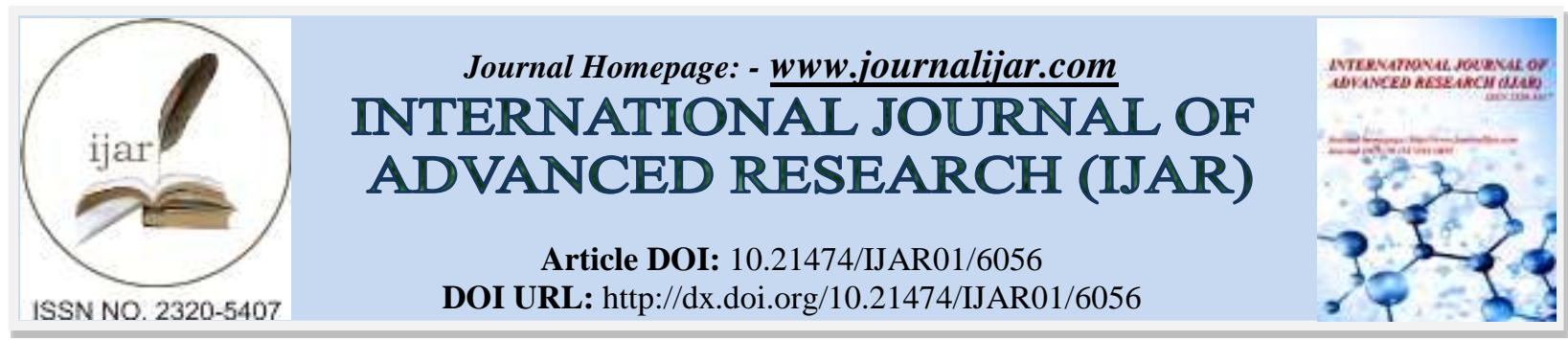

RESEARCH ARTICLE

\title{
COMPARISON OF DYNAMIC POSTURAL CONTROL OF COLLEGIATE ATHLETES IN DIFFERENT SPORTS.
}

Bahar Ateş.

Department of Coaching Training, University of Uşak, Faculty of Sport Sciences, 64100, Uşak, Turkey.

\section{Manuscript Info}

Manuscript History

Received: 14 October 2017

Final Accepted: 16 November 2017

Published: December 2017

\section{Abstract}

The purpose of this study was to determine if there were significant differences in dynamic postural control performance in male collegiate soccer and basketball players, wrestlers, and kickboxers. Sixty-five male collegiate athletes competing in soccer $(n=20)$, basketball $(n=14)$, wrestling $(\mathrm{n}=16)$, and kickboxing $(\mathrm{n}=15)$ volunteered to participate in this study. Star Excursion Balance Test (SEBT) scores were obtained bilaterally for anterior (ANT), posterolateral (PL), and posteromedial (PM) directions. Star Excursion Balance Test scores in the PL, PM, and composite reach distance were found higher in the wrestlers than the other groups $(\mathrm{p}<0.05)$. ANT scores did not differ between groups ( $p>0.05$ ). The results of this study demonstrated that soccer and basketball players and kickboxers did not differ in terms of dynamic balance. However, wrestlers demonstrated superior dynamic balance performance than others. To evaluate risks or deficits related to lower extremity injury in athletes, clinicians and coaches should consider dynamic balance performance differences between sports branches.

Copy Right, IJAR, 2017,. All rights reserved.

\section{Introduction:-}

Participation in sports among college students is on the rise and exercising on a regular basis has benefits to their health in many ways including the psychosocial benefits, higher levels of health-related fitness, socialization, competition and stress reduction ${ }^{1}$. However, muscle injuries are common in sports, and often occur during competition or training ${ }^{2}$. Athletic trainers often prescribe exercises in an attempt to enhance an athlete's postural control or balance and perhaps to reduce the risk of injury ${ }^{3}$.

Postural control is the process of coordinating corrective movement strategies and movements at the selected joints to remain in postural equilibrium ${ }^{4}$. Postural control can be grouped as either static or dynamic. Dynamic postural control is one of the athlete's ability to sustain whole body stability of the center of mass during switch between movements ${ }^{5}$. Although postural control or balance is not seen as a key factor for athletic performance ${ }^{6}$, the role of balance training seems to have a critical influence on neuromuscular control and functional performance ${ }^{7,8}$. Also, it is considered to be more important for many sports skills in terms of injury reduction ${ }^{-13}$ and has been identified as a risk factor for lower extremity injuries ${ }^{14}$. Therefore, the ability to control dynamic balance during movements is important and necessary for participation in sports ${ }^{15}$.

The control of balance during upright standing depends upon the central integration of afferent information from vestibular, proprioceptive, and visual systems ${ }^{1}$. These systems contribute to postural control, and numerous studies 
have shown that their stimulation evokes body sway $^{2},{ }^{16,17}$. In this context, sport training has been reported to improve postural capabilities ${ }^{18}$. However, it is reported that sports activities develop postural adaptations based on the sports branch ${ }^{17,19}$.

Although there are numerous studies about the evaluation of postural control of collegiate athletes in different sports $3,20,21$, athletes such as gymnasts, soccer players, and swimmers have shown to be superior in balance performance during experimental evaluations ${ }^{22}$. 23. Soccer players' balance ability also has been most widely compared with other athletes ${ }^{24}$. However, obtaining postural control results from combat sports such as wrestling, boxing, karate, taekwondo, judo, and fencing, where the athletes need special skills in balance control during matches $^{25}$, and comparing these results with others would be useful. By the way, it can be said that collegiate athletes and coaches are still in need for awareness of the importance of preseason examination, including reducing risks associated with future injuries, musculoskeletal screening, and balance performance testing in different sports. It is not possible to eliminate injuries in sports, but it can be possible to reduce the number and the risk of lower extremity injuries. Therefore, the primary purpose of this study is to describe dynamic postural control performance by sports, and to determine if there are any differences between collegiate soccer and basketball players kickboxers, and wrestlers. We hypothesized that Star Excursion Balance Test reach distances of wrestlers and kickboxers would be different from soccer and basketball players.

\section{Methodology:- \\ Participants:-}

A group of sixty-five active male collegiate athletes (soccer, $n=20$; basketball, $n=14$; wrestling, $n=16$; and kickboxing, $n=15$ ) volunteered to participate in this study. All athletes were free from significant musculoskeletal, cardiovascular, neurological, and vestibular disorders, had not suffered any lower extremity injuries within the past 6 months and muscle fatigue on the day of the assessment. Informed written consents were obtained from the athletes prior to participation in the study. The study was approved by the Health Science Ethics Committee (approval no: 2016-36). In addition, all experimental procedures were conducted in accordance with the Declaration of Helsinki.

\section{Protocol:-}

For all athletes, identical anthropometric measurements were taken. Before measurements, participants had removed their shoes and upper garments and dressed examination shorts and t-shirts. Modified Star Excursion Balance Test (SEBT) was used for dynamic postural control measurements of the participants. Leg lengths of each participant were measured bilaterally in centimeters at supine position from anterior superior iliac point to the distal part of medial malleolar. The measurements were taken randomly for dominant and non-dominant legs. Before balance test, each participant was requested to kick the ball and the foot used to kick the ball was recorded as dominant leg.

\section{Anthropometric Data:-}

Subjects' body masses were measured by using an electronic measuring scale, and height to the nearest centimeter was taken. Body mass index was calculated as weight $(\mathrm{kg})$ divided by height $\left(\mathrm{m}^{2}\right)$ squared.

\section{Dynamic Balance Test:-}

The SEBT was designed as a lower-extremity reach test on 8 designated lines on the ground ${ }^{26}$. The test later was simplified as to include only 3 directions as anterior, posteromedial, and posterolateral ${ }^{27}$. Internal consistency reliability of this scale is (ICC: $0.86-0.9)^{28}$. Bilateral reach distance was measured by using a tape measure fixed on the ground, and the reached point was marked on the tape measure for each direction of SEBT. The tape measures were positioned in connection with each other with $135^{\circ}$ angle opposite to the anterior points of posterior medial and posterior lateral areas. Anterior reach was measured from the toe tip at the center, posteromedial, and posterolateral were measured as the distance between the heel and the remotest point reached. The test requires the participants to be unshod in order to reach maximum distance with their free leg when their other leg is on the point of intersection of the star pattern on the floor. During the test process, the participants were required to keep their hands on iliac and keep their heels on the ground and to touch the remotest point with their toe tip. An experienced researcher made brief demonstration about the test before the measurement process, and the participants were asked to try to reach each direction at least 4 times $^{29}$. When the participants put their body weights on their reaching legs during measurements, when they disconnected their stance heels from the ground, or ceased to touch their hips, the process was repeated after the participant was verbally warned. All reach distances were recorded in centimeters. The average of reach-out scores for each direction was taken and normalized in accordance with the leg length values ${ }^{30}$. 
Normalized scores are shown as a percentage of stance leg length (LL\%). Normalized anterior, posteromedial, and posterolateral scores were averaged and combined score was found. Composite reach distance was calculated by the sum of the three reaching direction by averaging the normalized anterior, posteromedial, and posterolateral scores. The average values of normalized anterior, posteromedial, posterolateral, and composite scores from the right limb and left limb were used for statistical analysis.

\section{Statistical Analysis:-}

The formula (excursion distance/limb length $\mathrm{x} 100=\%$ MAXD) was used to determine normalized to limb length. Means, 95\% confidence intervals and standard deviations were calculated for all variables. Data normality was verified and confirmed by the Skewness and Kurtosis Tests. Kruskal-Wallis test was used to compare differences in descriptive parameters between groups. For the pairwise comparison Mann Whitney-U test was used. An alpha level of $\mathrm{p}<0.05$ was used to judge statistical significance. IBM SPSS, SPSS for Windows, Version 23 (IBM, Armonk, NY, USA) was used for all analyses.

\section{Results:-}

The participant characteristics by sports are presented in Table 1. There were no significant differences in age, body mass, and preferred leg among groups $(p>0.05)$. On the other hand, leg length in basketball players and kickboxers was significantly higher than wrestlers $(\mathrm{p}<0.05)$. Also, height in basketball players was significantly higher than wrestlers and leg length in kickboxers was significantly higher than wrestlers $(\mathrm{p}<0.05)$. In the normalized anterior, posteromedial, posterolateral, and composite reach distance, wrestlers had higher scores than basketball and soccer players and kickboxers (Figure 1). Table 2 shows the mean values and confidence intervals for each SEBT score analyzed, and differences in SEBT scores between groups. There were no significant group differences detected for the normalized anterior reach score ( $p>0.05$ ). But in the normalized posteromedial, posterolateral, and composite reach distance, a significant difference was observed between groups $(\mathrm{p}<0.05)$.

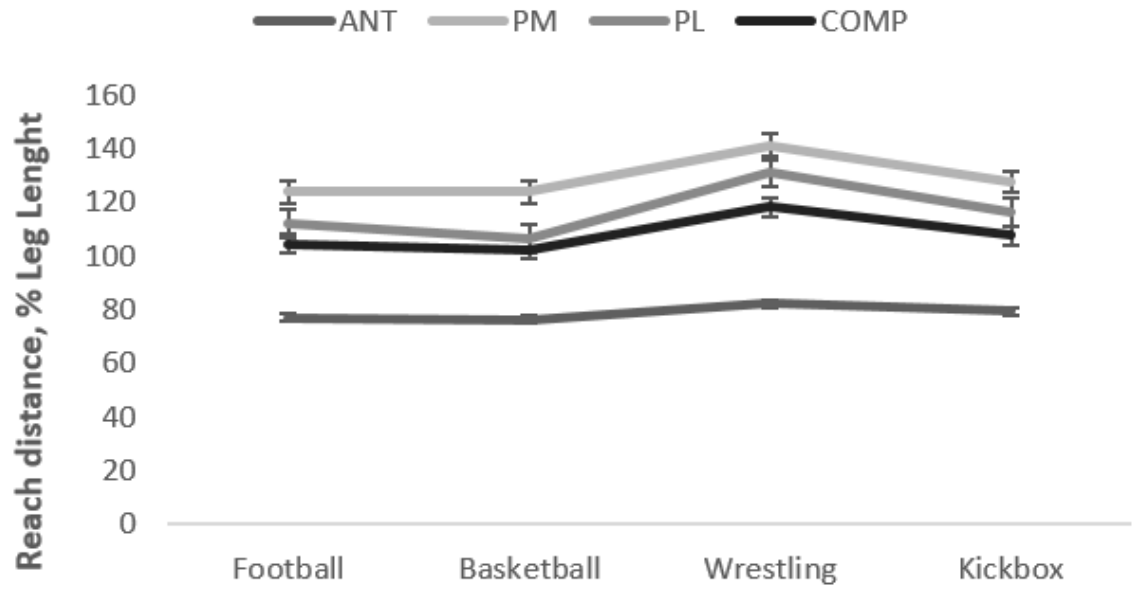

Sports

Figure 1:- Mean scores of normalized anterior, posteromedial, posterolateral, and composite reach distance by sports.

Table 1:- Mean \pm SD of the descriptive in soccer, basketball, wrestling and kickboxing athletes.

\begin{tabular}{|l|l|l|l|l|}
\hline \multirow{2}{*}{ Variables } & Group (Mean \pm SD) & Kickboxing \\
\cline { 2 - 5 } & Soccer & Basketball & Wrestling & K \\
\hline Age (years) & $20.7 \pm 2.03$ & $18.7 \pm 5.51$ & $20.2 \pm 1.43$ & $20.3 \pm 1.91$ \\
\hline Body mass $(\mathrm{kg})$ & $72.3 \pm 9.81$ & $80 \pm 13$ & $73.7 \pm 10.3$ & $70.5 \pm 6.9$ \\
\hline Body height(cm) & $178.5 \pm 6.45$ & $187.1 \pm 5.53 *$ & $175.9 \pm 7.41$ & $176.1 \pm 4.27$ \\
\hline Training age (years) & $8.5 \pm 2.42$ & $8.5 \pm 2.1$ & $7.9 \pm 1.8 \dagger$ & $5.4 \pm 3.62$ \\
\hline Limb length (cm) & $96 \pm 4.4$ & $105.3 \pm 6.09 *$ & $93.3 \pm 4.9$ & $98.5 \pm 3.91 \S$ \\
\hline & $\mathrm{N}(\%)$ & $\mathrm{N}(\%)$ & $\mathrm{N}(\%)$ & $\mathrm{N}(\%)$ \\
\hline Footedness & & & \\
\hline
\end{tabular}




\begin{tabular}{|l|l|l|l|l|l|}
\hline & Left limb & $6(30)$ & $4(28.6)$ & $2(12.5)$ & $3(20)$ \\
\hline & Right limb & $14(70)$ & $10(71.4)$ & $14(87.5)$ & $12(80)$ \\
\hline *Significant difference in relation to wrestlers $(p<0.05)$, + Significant difference in relation to kickboxers $(p<$ \\
0.05), \& Significant difference in relation to wrestlers $(p<0.05)$.
\end{tabular}

Table 2:- Comparison of mean SEBT score in soccer, basketball, wrestling and kickboxing athletes.

\begin{tabular}{|c|c|c|c|c|}
\hline \multirow[t]{2}{*}{ Score } & Soccer & Basketball & Wrestling & Kickboxing \\
\hline & M (CI 95\%) & M (CI 95\%) & M (CI 95\%) & $\mathrm{M}(\mathrm{CI} 95 \%)$ \\
\hline ANT (\%) & $77(73.3-80.7)$ & $76.3(69.4-83.3)$ & $82.3(79.8-84.9)$ & $79.3(75.3-85)$ \\
\hline PM (\%) & $124(119.5-128.4)$ & $124(113.4-134.5)$ & $141.3(135.8-146.7) * \dagger \S$ & $127.8(122.3-133.3)$ \\
\hline PL (\%) & $112.3(105.2-119.3)$ & $106.7(96-117.5)$ & $130.9(125.7-136.2) * \dagger \S$ & 116.4 (109.4-123.4) \\
\hline COMP (\%) & $104.4(99.9-108.9)$ & $102.3(93.4-111.2)$ & $118.2(114.4-121.9) * \dagger \S$ & $107.8(102.9-112.7)$ \\
\hline \multicolumn{5}{|c|}{$\begin{array}{l}\text { ANT = anterior; } P M=\text { posteromedial; } P L=\text { posterolateral; COMP = composite, M: Mean, CI: confidence interval, } \\
\text { Test: Kruskal Wallis *Significant difference in relation to soccer, basketball and kickboxing groups }(p<0.05) ; \\
\text { Significant difference in relation to soccer, basketball and kickboxing groups }(p<0.05) ; \S \text { Significant difference in } \\
\text { relation to soccer, basketball and kickboxing groups }(p<0.05) \text {. }\end{array}$} \\
\hline
\end{tabular}

\section{Discussion:-}

The results of this study indicate that there is a significant difference in dynamic postural control of collegiate athletes in different sports. We found that collegiate wrestlers demonstrated superior reach distances in the posteromedial, posterolateral, and composite directions of the SEBT than other groups. This is in line with this study's hypothesis, which is based on previous research by Stiffler and et al. (2015) who found that collegiate wrestlers reach the farthest posteromedial, posterolateral directions and composite scores. In addition, Feizolahi and Azarbayjani (2015), reported that male collegiate martial arts and wrestling athletes had better dynamic balance scores than soccer players, gymnasts, weight lifters, and basketball players. In this study, kickboxers also exhibited greater dynamic balance in the normalized ANT, PM, PL, and COMP distance than soccer and basketball players. This superior dynamic balance ability observed in the wrestlers and kickboxers might be explained by the lot of posture-kinetic activities in sports practices ${ }^{17}$. Since they use the stimulus of muscular, articular, and cutaneous mechanoreceptors to adapt to the constant modifications of posture, support, ground and partner contact, each athlete learns to adapt to unstable dynamic situations to turn them into his advantage during combats ${ }^{32}$.

This study found that soccer and basketball players had approximate values in terms of dynamic balance performance on the SEBT. It has been stated in the literature that after gymnasts, soccer players tended to have the best balance ability ${ }^{24}$. Some researchers also reported that gymnasts and soccer players did not differ in terms of dynamic balance performance and basketball players had inferior dynamic balance performance than soccer players $^{3,33}$. Soccer players often perform shooting, dribbling, and passing skills during a match ${ }^{34}$. They need to maintain single limb balance while performing these skills, which requires a high level dynamic balance ${ }^{22,}{ }^{34}$. In contrast to these previous studies, this current study determined that soccer and basketball players had approximate values in terms of dynamic balance performance on the SEBT. This can be explained as anthropometric characteristics of the two groups and specifically similarity in height. Having a higher center of gravity, athletes were not able to balance as effectively as the athletes who had the advantage of less height ${ }^{35}$.

A review of the literature 25 has proved that postural control impairment can both decrease performance and increase risk of injuries. An altered neuromuscular control strategy, increased intersegmental joint forces, and corresponding increased forces developed about the articular, ligamentous, and musculature structures cause increased variation in postural stability and affect the ability of athletes to control the position of their center of gravity. As stated by Kalirathinam et al. (2016), as well as Pourkazemi et al. (2016), low balance ability is a risk factor for injuries to the lower limbs in athletes. Butler et al. (2012), who tested fifty-nine collegiate American football players on Lower Quarter Y-Balance Test protocol YBT-LQ, reported that collegiate football players with less than $89.6 \%$ score, had substantial possibility of sustaining a greater risk of non-contact lower extremity injury 3.5 times. A study was carried out by Turkish Ministry of Youth and Sports on thirteen thousand certified athletes in 31 different sports, and it was reported that most injuries occurred in basketball ${ }^{38}$.

As with any research, this study is not without limitations. Group differences of this present study have only been documented for male athletes. This was the first limitation of the study. Female athletes should also be considered if 
these differences are consistent. Second limitation of the study is that it only covers collegiate athletes. Better results will be obtained, if this study is conducted on larger groups of participants from various sports branches. However, athletes, coaches, and clinicians may use these results to identify balance performance profiles of young athletes.

\section{Conclusions:-}

In conclusion, wrestlers exhibited greater overall dynamic postural control than soccer and basketball players and kickboxers. Trainers and athletes should give further consideration to test and enhance dynamic balance performance, especially in pre-season. Furthermore, the optimal training programs are required to enhance dynamic balance performance in those athletes with low scores, and to reduce the risk of non-contact lower extremity injuries.

\section{Acknowledgement:-}

I would like to thank Dr. Dilşat Yıldırım Bingül (Dışkapı Yıldırım Beyazıt Training and Research Hospital for her contribution.

\section{References:-}

1. Agel, J., Ransone, J., Dick, R., Oppliger, R., Marshall, S.W. (2007): Descriptive epidemiology of collegiate men's wrestling injuries: National Collegiate Athletic Association Injury Surveillance System, 1988-1989 through 2003-2004. J Athl Train., 42: 303-310.

2. Anderson, K., Strickland, S.M., Warren, R. (2001): Hip and groin injuries in athletes. Am J Sports Med., 29: 521-533.

3. Bressel, E., Yonker, J.C., Kras, J., Heath, E.M. (2007): Comparison of static and dynamic balance in female collegiate soccer, basketball, and gymnastics athletes. J Athl Train., 42: 42-46.

4. Butler, R.J., Southers, C., Gorman, P.P., Kiesel, K.B., Plisky, P.J. (2012): Differences in soccer players' dynamic balance across levels of competition. J Athl Train., 47: 616-620.

5. Davlin, C.D. (2004): Dynamic balance in high level athletes. Perceptual and motor skills., 98: 1171-1176.

6. Emery, C.A., Roy, T.O., Whittaker, J.L., Nettel-Aguirre, A., Van Mechelen, W. (2015): Neuromuscular training injury prevention strategies in youth sports: a systematic review and meta-analysis. Br J Sports Med., 49: 865870.

7. Feizolahi, F., Mohammad-Ali, A. (2015): Comparison of static and dynamic balance in amateur male athletes. Rehabil Med., 3: 89-98.

8. Filingeri, D., Bianco, A., Zangla, D., Paoli, A., Palma, A. (2012): Is karate effective in improving postural control?. Loughborough University Institutional Repository., 8: 191-194.

9. Gray, G.W. (1995): Lower Extremity Functional Profile. Adrian, MI: Wynn Marketing, Inc.

10. Gribble, P.A., Hertel, J. (2004): Changes in postural control during a 48-hr. sleep deprivation period. Percept Mot Skills., 99: 1035-1045.

11. Gribble, P.A., Hertel, J., Plisky, P. (2012): Using the Star Excursion Balance Test to assess dynamic posturalcontrol deficits and outcomes in lower extremity injury: a literature and systematic review. J Athl Training., 47: 339-357.

12. Gribble, P.A., Kelly, S.E., Refshauge, K.M., Hiller, C.E. (2013): Interrater reliability of the Star Excursion Balance Test. J Athl Train., 48: 621-626.

13. Hertel, J., Olmsted-Kramer, L.C. (2007): Deficits in time-to-boundary measures of postural control with chronic ankle instability. Gait Posture., 25: 33-9.

14. Hrysomallis, C. (2011): Balance ability and athletic performance. Sports Med., 41: 221-232.

15. http://www.hurriyet.com.tr/turkiye-spor-tarihinin-en-kapsamli-arastirmasi-22332050. 11.10.2017

16. Jaco Ras, M., Puckree, T. (2014): Injury incidence and balance in rugby players. Pak J Med Sci., 30: 13461350.

17. Järvinen, T.A., Järvinen, T.L., Kääriäinen, M., Kalimo, H., Järvinen, M. (2005): Muscle injuries biology and treatment. Am J Sportss Med., 33: 745-764.

18. Kalirathinam, D., et al. (2016): Effect of neuromuscular training in the rehabilitation of ankle lateral ligament injuries-a review. Health Sci J., 10: 1-10.

19. Kejonen, P. (2002): Body Movements during Postural Stabilization (dissertation). Department of Physical Medicine and Rehabilitation. Oulu Univ.

20. Kioumourtzoglou, E., Derri, V., Tzetzls, G., Theodorakis, Y. (1998): Cognitive, perceptual, and motor abilities in skilled basketball performance. Perceptual and motor skills., 86: 771-786. 
21. Kochanowicz, A., Kochanowicz, K., Niespodziński, B., Mieszkowski, J., Sawicki, P. (2017): Effects of Systematic Gymnastic Training on Postural Control in Young and Adult Men. Science of Gymnastics Journal., 9: 5-15.

22. Leong, H.T., Fu, S.N., Ng, G.Y., Tsang, W.W. (2011): Low-level Taekwondo practitioners have better somatosensory organisation in standing balance than sedentary people. European Journal of Applied Physiology., 111: 1787-1793.

23. Matsuda, S.D., Masanobu, U. (2008): Centre of pressure sway characteristics during static one-legged stance of athletes from different sports. J Sports Sci., 26: 775-779.

24. McGuine, T.A., Greene, J.J., Best, T., Leverson, G. (2000): Balance as a predictor of ankle injuries in high school basketball players. Clin J Sports Med., 10: 239-244.

25. Orchard J. (2002): Is there a relationship between ground and climatic conditions and injuries in football? Sports Med., 32: 419-32.

26. Paillard, T., Noe F., Riviere, T., Marion, V., Montoya, R., Dupui, P. (2006): Postural Performance and Strategy in the Unipedal Stance of Soccer Players at Different Levels of Competition. Journal of Athletic Training., 41: $172-176$.

27. Paterno, M.V., Myer, G.D., Ford, K.R., et al. (2000): Neuromuscular training improves single-limb stability in young female athletes. J Orthop Sports Phys Ther., 34: 305-16.

28. Pourkazemi, F., Hiller, C., Raymond, J., Black, D., Nightingale, E., Refshaug, K. (2016): Using balance tests to discriminate between participants with a recent index lateral ankle sprain and healthy control participants: a cross-sectional study. J Athl Train., 51: 213-222.

29. Riemann, B.L., Guskiewicz, K.M., Shields, E.W. (1999): Relationship between clinical and forceplate measures of postural stability. J Sport Rehabil., 8: 71-82.

30. Riva, D., Bianchi, R., Rocca, F., Mamo, C. (2016): Proprioceptive training and injury prevention in a professional men's basketball team: a six-year prospective study. J Strength Cond., 30: 461-475.

31. Robinson, R.H., Gribble, P.A. (2008): Support for a reduction in the number of trials needed for the star excursion balance test. Arch Phys Med Rehabil., 89: 364-370.

32. Steffen, K., et al. (2013): High adherence to a neuromuscular injury prevention programme (FIFA 11+) improves functional balance and reduces injury risk in Canadian youth female football players: a cluster randomised trial. Br J Sportss Med., 47: 794-802.

33. Stiffler, M.R., Sanfilippo, J.L., Brooks, M.A., Heiderscheit, B.C. (2015): Star Excursion Balance Test performance varies by sports in healthy Division I collegiate athletes. J Orthop Sports Phys Ther., 45: 772-780.

34. Thorpe, J.L., Ebersole, K.T. (2008): Unilateral balance performance in female collegiate soccer athletes. The Journal of Strength and Conditioning Research., 22: 1429-1433.

35. Ulrich, B.D., Ulrich, D.A. (1985): The role of balancing in performance of fundamental motor skills in 3-, 4and 5-year-old children. In: Clark JE, Humphrey J, editors. Motor development. Current selected research. Princeton: Princeton Book Co.

36. Waldén, M., Krosshaug, T., Bjørneboe, J., et al. (2015): Three distinct mechanisms predominate in non-contact anterior cruciate ligament injuries in male professional football players: a systematic video analysis of 39 cases. Br J Sports Med., 49: 1452-60.

37. Zech, A., Hübscher, M., Vogt, L., Banzer, W., Hänsel, F., Pfeifer, K. (2010): Balance training for neuromuscular control and performance enhancement: a systematic review. J Athl Train., 45: 392-403.

38. Zemková, E. (2014): Sports-specific balance. Sports Med., 44: 579-590. 